\title{
Application of minidisk infiltrometer to estimate water repellency in Mediterranean pine forest soils
}

\author{
Vincenzo Alagna $^{1}$, Massimo Iovino ${ }^{1 *}$, Vincenzo Bagarello ${ }^{1}$, Jorge Mataix-Solera ${ }^{2}$, L’ubomír Lichner $^{3}$ \\ ${ }^{1}$ Dipartimento di Scienze Agrarie e Forestali, Università degli Studi di Palermo, Viale delle Scienze, Ed. 4 Ingr. E, 90128 Palermo, Italy. \\ 2 Departamento de Agroquímica y Medio Ambiente, Universidad Miguel Hernández, Edificio Alcudia, Avda de la Universidad, 03202 \\ Elche Alicante, Spain. \\ ${ }^{3}$ Institute of Hydrology, Slovak Academy of Sciences, Dúbravská cesta 9, 84104 Bratislava, Slovak Republic. \\ * Corresponding author. Tel.: +39 091 23897070. Fax: +39 091 484035. E-mail: massimo.iovino@unipa.it
}

\begin{abstract}
Assessment of soil water repellency (SWR) was conducted in the decomposed organic floor layer (duff) and in the mineral soil layer of two Mediterranean pine forests, one in Italy and the other in Spain, by the widely-used water drop penetration time (WDPT) test and alternative indices derived from infiltration experiments carried out by the minidisk infiltrometer (MDI). In particular, the repellency index (RI) was calculated as the adjusted ratio between ethanol and water soil sorptivities whereas the water repellency cessation time (WRCT) and the specifically proposed modified repellency index $\left(\mathrm{RI}_{\mathrm{m}}\right)$ were derived from the hydrophobic and wettable stages of a single water infiltration experiment. Time evolution of SWR and vegetation cover influence was also investigated at the Italian site. All indices unanimously detected severe SWR conditions in the duff of the pine forests. The mineral subsoils in the two forests showed different wettability and the clay-loam subsoil at Ciavolo forest was hydrophobic even if characterized by organic matter (OM) content similar to the wettable soil of an adjacent glade. It was therefore assumed that the composition rather than the total amount of OM influenced SWR. The hydraulic conductivity of the duff differed by a factor of 3.85.8 between the two forested sites thus influencing the vertical extent of SWR. Indeed, the mineral subsoil of Javea showed wettable or weak hydrophobic conditions probably because leaching of hydrophobic compounds was slowed or prevented at all. Estimations of SWR according to the different indices were in general agreement even if some discrepancies were observed. In particular, at low hydrophobicity levels the SWR indices gathered from the MDI tests were able to signal sub-critical SWR conditions that were not detected by the traditional WDPT index. The WRCT and modified repellency index $\mathrm{RI}_{\mathrm{m}}$ yielded SWR estimates in reasonable agreement with those obtained with the more cumbersome RI test and, therefore, can be proposed as alternative procedures for SWR assessment.
\end{abstract}

Keywords: Pine forest; Soil water repellency; Minidisk infiltrometer; Modified repellency index.

\section{INTRODUCTION}

Fast-growing protective woodlands, mostly of evergreen trees including pine and eucalyptus, have been planted in large marginal areas in the Mediterranean region to tackle land degradation and control water runoff, soil erosion and compaction, landslides, and organic matter decline (Iovino et al., 2016). Resins, waxes, aromatic oils and other organic substances in the tissues of these trees can cause organic coating on soil particles which is responsible of soil water repellency (SWR) or hydrophobicity (Doerr et al., 2000). Hydrological processes can be affected by SWR through reduced matrix infiltration, development of fingered flow, irregular wetting fronts, and overall increased runoff generation and soil erosion (Cerdà and Doerr, 2007; DeBano, 2000; Doerr et al., 2000).

Hydrophobicity is not a static soil property but is known to follow short-term or seasonal variations. It is generally found to be most extreme when soils are dry, declining and eventually disappearing as soils become wet (e.g., de Jonge et al., 1999; Dekker and Ritsema, 1994; Fér et al., 2016; Lichner et al., 2013a; Vogelmann et al., 2013) although the soil moisture water repellency relationship is nevertheless complex (Doerr et al., 2000). When wet, amphiphilic compounds produced by plants are hydrophilic, but below a critical moisture threshold, their hydrophilic ends are bond strongly with one another and the soil particles, while hydrophobic ends are oriented towards the free space inducing water repellency (Ma'shum and Farmer, 1985; Tschapek, 1984). Severe water repellency is therefore expected following prolonged dry, warm summers that are typical of Mediterranean region with a transition from water repellent (hydrophobic) to wettable (hydrophilic) conditions during the autumn/winter months (Buczko et al., 2005; Lichner et al., 2013a; Rodríguez-Alleres et al., 2007).

The vertical extent of hydrophobicity within soil profiles was reported to vary from only a few centimeters (Buczko et al., 2002; Jungerius and Dejong, 1989) to over $50 \mathrm{~cm}$ depth (Dekker and Ritsema, 1994). In young pine forest, it is expected that SWR is limited to the decomposed organic floor layer (duff) including large amount of partially decomposed vegetal material (Doerr et al., 1996). However, the extent and the conditions under which hydrophobic compounds influence SWR of underlying mineral soils remain unclear (Buczko et al., 2002). The persistence of soil water repellency can be quantitatively characterized either in the field or in the laboratory by the water drop penetration time (WDPT) test that consists of placing a drop of water on the soil surface and measuring the time for it to penetrate (Van't Woudt, 1959; Watson and Letey, 1970). WDPT value determines how long water repellency persists in the contact area between a water droplet and the soil surface. A soil is considered to be water repellent if the WDPT exceeds $5 \mathrm{~s}$ (Doerr, 1998).

The adjusted ratio between the soil-ethanol and soil-water sorptivities was proposed as a measure of the degree of hydrophobicity (Tillman et al., 1989). At the aim of estimating soil sorptivity, tension infiltration experiments are preferred to ponded ones to exclude the contribution of macropores that 
may overwhelm soil hydrophobicity (Cerdà, 1996; Ebel et al., 2012; Nyman et al., 2010). Miniaturized tension infiltrometers were proposed to determine SWR (Hallett et al., 2001; Vogelmann et al., 2013), but their use is confined to the aggregate scale and, for field use, standard infiltrometers are more suited. Hunter et al. (2011) assessed the influence of disk size suggesting that the minidisk infiltrometer (MDI), having a 45 $\mathrm{mm}$ diameter disk, is appropriate for field assessment of SWR. In a recent investigation, the MDI proved to be a practical alternative to the classical tension infiltrometer to estimate hydrodynamic properties of a loam soil (Alagna et al., 2016). Furthermore, repellency assessment based on MDI tests appears inherently scaled to account for soil physical properties other than hydrophobicity (e.g., the volume, connectivity and the geometry of pores) that directly influence the hydrological processes.

Lichner et al. (2013b) assessed hydrophobicity of biological soil crusts by the water repellency cessation time (WRCT), estimated from the intersection of the two straight lines representing the cumulative infiltration vs. square root of time relationship for hydrophobic and near wettable conditions. For their miniaturized tension infiltration experiments, the WRCT increased with an increase in WDPT despite coefficients of determination were hardly significant (Lichner et al., 2013b). Use of WRCT to assess SWR from field experiments conducted by the MDI are still lacking in literature and there is the need to test the reliability of this index also considering the potential advantages that stem from its simplicity (small volumes of water, only one test site).

The objective of this research was to test alternative indices for assessing SWR from infiltration experiments conducted with the MDI in two Mediterranean pine woodlands. In particu- lar, the investigation was focused on the capability of MDI experiments carried out with either ethanol and water or water alone to assess SWR and to better understand the vertical evolution of SWR into the upper part of a forest soil profile.

\section{MATERIALS AND METHODS}

The investigation was conducted in two managed pine woodlands of the coastal Mediterranean region that can be considered representative of the reforestations widely applied in the past decades to tackle land degradation (Figure 1). The first site is located in the artificial woodland of Ciavolo close to Marsala, Italy $\left(37^{\circ} 45^{\prime} 40.6^{\prime \prime} \mathrm{N}, 12^{\circ} 34^{\prime} 09.0^{\prime \prime} \mathrm{E}\right)$. Elevation is 105 $\mathrm{m}$ a.s.l. and surface slope is low (4.4\%). The soil is a Typic Rhodoxeralf (Soil Survey Staff, 2014) with a depth of 0.40$0.60 \mathrm{~m}$ and the parent material is calcareous sandstone. According to USDA classification, the soil texture is clay loam (Table 1).

Two sampling sites (approximately $5 \times 5 \mathrm{~m}^{2}$ each) were arranged in an area including 30 years old Pinus pinaster trees. The first sampling site was located under the tree canopy fully covering the soil surface (site CF), the second sampling site was located in a glade vegetated with spontaneous annual grasses (Avena fatua L., Galactites elegans (All.) Soldano, Hypochaeris achyrophorus L., Oxalis pes-caprae L. and Vulpia ciliata Dumort) (site CG). The second site was selected for comparative purposes given that any effect of pine stands on SWR can be excluded in this case due to the distance (approximately $50 \mathrm{~m}$ ) between the two sites. In site CF, both the $5-\mathrm{cm}$ thick surface duff formed by decomposed vegetal material (CFO) and the underlying 5-cm thick mineral soil layer (CFM) were sampled two times in 2014, at exactly the same location, to explore different initial soil moisture conditions. The first

Table 1. Physical and chemical properties of soils from the Mediterranean pine woodland sites at Ciavolo (Italy) and Javea (Spain).

\begin{tabular}{|c|c|c|c|c|c|c|c|c|}
\hline Site & Depth $(\mathrm{cm})$ & Soil texture & Sand (\%) & $\begin{array}{l}\text { Silt } \\
(\%)\end{array}$ & $\begin{array}{l}\text { Clay } \\
(\%)\end{array}$ & $\begin{array}{c}\mathrm{CaCO}_{3} \\
(\%)\end{array}$ & $\begin{array}{c}\mathrm{pH} \\
\left(\mathrm{H}_{2} \mathrm{O}\right)\end{array}$ & $\begin{array}{c}\mathrm{pH} \\
\left(\mathrm{CaCl}_{2}\right)\end{array}$ \\
\hline Ciavolo (forest) & $5-10$ & clay-loam & 23.6 & 43.0 & 33.4 & 2.05 & 7.39 & 6.76 \\
\hline Ciavolo (glade) & $0-10$ & clay-loam & 36.9 & 34.5 & 28.5 & 3.80 & 7.77 & 6.97 \\
\hline Javea & $5-10$ & silty-clay & 15.7 & 43.3 & 40.8 & 4.11 & 7.55 & 6.78 \\
\hline
\end{tabular}

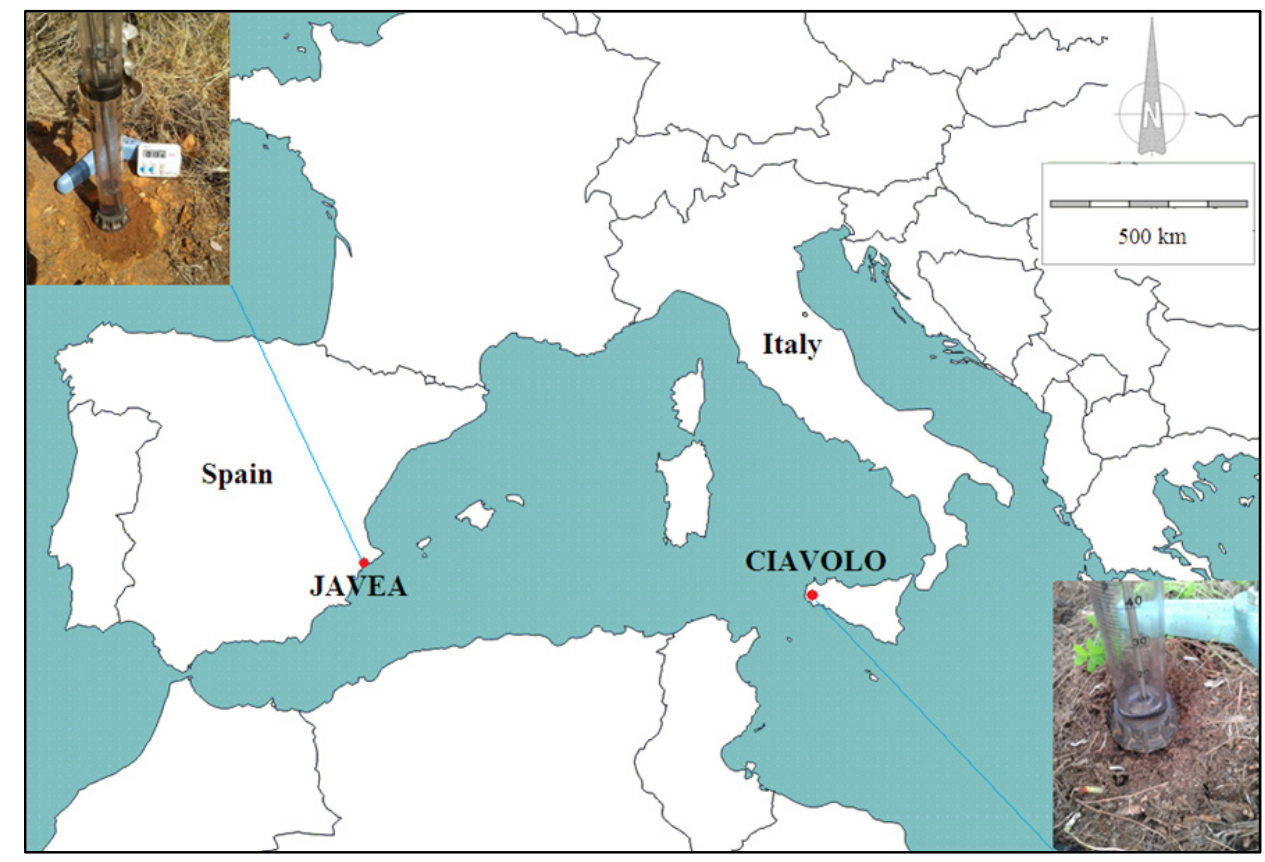

Fig. 1. Location of experimental sites. 
sampling was conducted in late summer (from 11th to 22nd September) after a long dry period. Cumulative precipitation in the three months prior to sampling was $4.8 \mathrm{~mm}$, whereas mean daily air temperature was $24.6^{\circ} \mathrm{C}$. The second sampling was conducted from 24th November to 3rd December after $108 \mathrm{~mm}$ rainfalls had occurred that is approximately $20 \%$ of the average annual precipitation for the location. Average air temperature on the two sampling dates were $24.7^{\circ} \mathrm{C}$ and $18.2^{\circ} \mathrm{C}$, respectively. Only the $5-\mathrm{cm}$ thick surface layer of mineral soil was sampled in the glade at the second date (CGM) given that a well-developed organic layer was not detectable in this case.

The second experimental site is located at Javea close to Alicante, Spain (38॰48'15.0"N 009'18.8"E, elevation $213 \mathrm{~m}$ a.s.l.), in a 40-years old afforested plantation of Pinus halepensis (site JF). In the past, the site was cultivated as shown by the presence of abandoned agricultural terraces. The soil is Lithic Rhodoxeralf (Soil Survey Staff, 2014) developed over a karstified limestone with variable depth, generally lower than $0.5 \mathrm{~m}$. According to USDA classification, the soil is silty clay (Table 1). On $8^{\text {th }}$ and $16^{\text {th }}$ July 2015 , the surface duff (JFO) and the underlying mineral soil layer (JFM) were sampled at a selected flat area (approximately $5 \times 5 \mathrm{~m}^{2}$ ) located under the tree canopy. The mean daily air temperature at the two sampling dates were, respectively, $27.1{ }^{\circ} \mathrm{C}$ and $26.0^{\circ} \mathrm{C}$. No rainfall occurred in between the two dates and in the three months prior to sampling. In the same period (April to June) the mean daily air temperature was $21.1^{\circ} \mathrm{C}$. Only dry soil moisture condition was sampled at Javea site given the main focus of the study was on the SWR distribution in the upper soil profile of the two Mediterranean pine forests. Hereinafter, information from the seven sets of data, resulting from different sites, vegetation habitats, sampling depths and initial soil water contents, is abbreviated as follows: C: Ciavolo, J: Javea, F: pine forest, G: glade with spontaneous grass vegetation, O: decomposed organic floor layer (duff), M: mineral soil, 1: first sampling date, 2: second sampling date.

For each sampling condition (i.e., for each soil layer and time of sampling), 10 undisturbed soil cores $(0.05 \mathrm{~m}$ in height by $0.05 \mathrm{~m}$ in diameter) were randomly collected to determine soil bulk density, $\rho_{b}\left(\mathrm{Mg} \mathrm{m}^{-3}\right)$, and volumetric water content at the time of sampling, $\theta_{0}\left(\mathrm{~m}^{3} \mathrm{~m}^{-3}\right)$. Scrubbed soil samples were also collected to determine organic matter $(\mathrm{OM})$ content by the Walkley-Black method (Nelson and Sommers, 1996). The water drop penetration time (WDPT) test was carried out by placing 30 drops of deionized water in different smoothed locations within the sampling area from a standard height of 10 $\mathrm{mm}$ and recording the time for their complete penetration, A medical dropper was used that yielded drops of uniform volume $(70 \pm 5 \mu \mathrm{L})$. Despite there is not a standard protocol for WDPT measurement, this drop size was close to the minimum volume recommended by Hallin et al. (2013) to accurately account for soil microtopographical variability. According to these authors, the applied protocol allows estimating the mean WDPT value with an error of $\pm 10 \%$ at $95 \%$ confidence. For long infiltration time (WDPT $>600 \mathrm{~s}$ ) the drop was protected from direct sun and covered by a plastic can to limit evaporation. Five classes of repellency were considered according to Dekker and Ritsema (1994): wettable (WDPT $\leq 5 \mathrm{~s})$; slightly water repellent $(5<$ $\mathrm{WDPT} \leq 60 \mathrm{~s})$; strongly water repellent $(60<\mathrm{WDPT} \leq 600 \mathrm{~s})$; severe water repellent $(600<\mathrm{WDPT} \leq 3600 \mathrm{~s})$ and extremely water repellent (WDPT $>3600 \mathrm{~s}$ ).

Twenty tension infiltration tests were conducted by a standard MDI (Decagon Devices, Inc., Pullman, WA). Both 95\% ethanol and deionized water were used, setting the applied pressure head at $-2 \mathrm{~cm}$ to reduce macropore flow (Beatty and
Smith, 2013; Hallett et al., 2001; Lichner et al., 2013b) and placing the disk of the MDI directly on the soil surface previously levelled using a small amount of 2-mm sieved soil collected near the infiltration point. Cumulative infiltration of ethanol was visually recorded at the MDI reservoir at intervals of $10 \mathrm{~s}$ for the first minute, every $30 \mathrm{~s}$ for the successive two minutes and, finally, every one minute until the complete infiltration of approximately $0.08 \mathrm{~L}$ of ethanol, corresponding to a cumulative infiltration height of $50 \mathrm{~mm}$. Infiltration of water was much slower than infiltration of ethanol and, therefore, measurement intervals were increased up to $15 \mathrm{~min}$. The influence of temperature on SWR measurements was considered negligible given that field tests within an experimental condition (i.e., given site, soil layer and vegetation habitat) were completed in no more than 1-2 days during which the differences in temperature were small and, in any cases, influenced the different SWR indices in a comparable way.

Soil sorptivity was estimated as the slope of the regression line between the early-time cumulative infiltration, $I(\mathrm{~L})$, and square root of time, $t$ (T) (Philip, 1957). According to Tillman et al. (1989), the repellency index, RI, is the adjusted ratio of ethanol sorptivity, $S_{e}\left(\mathrm{~L} \mathrm{~T}^{-0.5}\right)$, to water sorptivity, $S_{w}\left(\mathrm{~L} \mathrm{~T}^{-0.5}\right)$ (i.e., RI $=1.95 S_{e} / S_{w}$ ). However, measurements of $S_{e}$ and $S_{w}$ cannot be performed sequentially at the same point since the initial conditions change between the two fluids whereas pairwise measurements of $S_{e}$ and $S_{w}$ may result in possible misestimating of RI due to soil heterogeneity. In this study, the approach proposed by Pekárová et al. (2015) was followed that considers 100 estimates of RI obtained from all possible combinations of $10 S_{e}$ by $10 S_{w}$ measurements at each sampling site. By this approach, the statistics of RI are derived from the empirical frequency distribution which accounts for overall spatial variability of SWR. The RI estimated according to Pekárová et al. (2015) is also referred to as combined repellency index. For comparative purposed, RI was also calculated from the mean $S_{e}$ and $S_{w}$ values at each of seven experimental conditions. Using water infiltration data, the water repellency cessation time (WRCT) was estimated as the intersection between the two regression lines representing the early-time (hydrophobic) and late-time (wettable) soil conditions in a $I$ vs. $t^{0.5}$ graph (Lichner et al., 2013b). The same graph allowed to calculate a modified repellency index $\mathrm{RI}_{\mathrm{m}}$ as the ratio of the sorptivities in the two stages of the infiltration process (Sepehrnia et al., 2016).

The analysis of the statistical distribution of a given set of data was carried out by the Lilliefors (1967) test at $P=0.05$. Only the normal and the log-normal distributions were considered because soil physical properties were often found to be adequately described by these distributions (Warrick, 1998). The mean and the coefficient of variation (CV) of a given dataset were calculated according to the statistical distribution better describing the experimental data (Lee et al., 1985). Outliers in dataset were detected as values falling above or below 1.5 times the interquartile range (Helsel and Hirsch, 2002) and excluded from the following statistical analyses. Comparisons between mean values were conducted by a t-test $(P=0.05)$, either homoscedastic or not according to an $F$-test $(P=0.05)$.

\section{RESULTS AND DISCUSSION}

For both forest sites (CF and JF), summer sampling yielded significantly lower and more variable soil water contents in the surface duff than in the underlying mineral soil (Table 2). A significant increase of soil moisture of the duff but not of the underlying mineral soil was observed between the two sampling dates at Ciavolo. As a consequence of rainfall that occurred 
Table 2. Statistics of initial soil water content $\left(\theta_{0}\right)$, bulk density $\left(\rho_{b}\right)$, and organic matter content $(\mathrm{OM})$ for different sampling depths and dates at the experimental sites of Ciavolo (C) (Italy) and Javea (J) (Spain) where F. forest, G: glade, O: decomposed organic floor layer (duff), M: mineral soil; 1: first sampling; 2: second sampling, $N$ : sample size.

\begin{tabular}{|c|c|c|c|c|c|c|c|}
\hline & \multicolumn{5}{|c|}{ Ciavolo } & \multicolumn{2}{|c|}{ Javea } \\
\hline & CFO1 & CFO2 & CFM1 & CFM2 & CGM2 & JFO1 & JFM1 \\
\hline & \multicolumn{7}{|c|}{ Initial water content, $\theta_{0}\left(\mathrm{~cm}^{3} \mathrm{~cm}^{-3}\right)$} \\
\hline $\mathrm{N}$ & 10 & 10 & 9 & 10 & 10 & 10 & 8 \\
\hline $\min$ & 0.104 & 0.149 & 0.149 & 0.155 & 0.245 & 0.033 & 0.054 \\
\hline $\max$ & 0.160 & 0.199 & 0.180 & 0.182 & 0.312 & 0.114 & 0.139 \\
\hline \multirow{2}{*}{ mean } & 0.128 & 0.175 & 0.166 & 0.169 & 0.281 & 0.066 & 0.098 \\
\hline & (a),(c) & (a),d & $\mathrm{b},(\mathrm{c})$ & $\mathrm{b}, \mathrm{d},(\mathrm{e})$ & (e) & (f) & (f) \\
\hline CV (\%) & 16.9 & 8.01 & 6.33 & 5.80 & 7.51 & 36.9 & 29.2 \\
\hline & \multicolumn{7}{|c|}{ Bulk density, $\rho_{b}\left(\mathrm{~kg} \mathrm{~m}^{-3}\right)$} \\
\hline $\mathrm{N}$ & 10 & 10 & 9 & 10 & 10 & 10 & 8 \\
\hline $\min$ & 0.450 & 0.641 & 1.108 & 1.011 & 1.120 & 0.181 & 0.817 \\
\hline $\max$ & 1.077 & 0.891 & 1.242 & 1.219 & 1.291 & 0.864 & 1.276 \\
\hline \multirow{2}{*}{ mean } & 0.725 & 0.749 & 1.172 & 1.089 & 1.192 & 0.548 & 1.082 \\
\hline & $\mathrm{a},(\mathrm{c})$ & $\mathrm{a},(\mathrm{d})$ & (b), (c) & (b), (d), (e) & (e) & (f) & (f) \\
\hline CV (\%) & 32.4 & 9.5 & 4.14 & 5.70 & 4.73 & 45.5 & 14.9 \\
\hline & \multicolumn{7}{|c|}{ Organic matter content, OM (\%) } \\
\hline $\mathrm{N}$ & 10 & 10 & 10 & 10 & 10 & 10 & 10 \\
\hline $\min$ & 19.10 & 21.31 & 4.60 & 3.80 & 4.43 & 22.7 & 8.22 \\
\hline $\max$ & 21.66 & 21.74 & 4.80 & 4.04 & 5.00 & 28.7 & 8.87 \\
\hline \multirow{2}{*}{ mean } & 20.03 & 21.48 & 4.66 & 3.93 & 4.71 & 26.6 & 8.54 \\
\hline & $\mathrm{a},(\mathrm{c})$ & $\mathrm{a},(\mathrm{d})$ & (b), (c) & (b), (d), (e) & (e) & (f) & (f) \\
\hline CV (\%) & 7.04 & 1.07 & 2.41 & 3.11 & 6.02 & 12.6 & 3.83 \\
\hline
\end{tabular}

Mean values followed by the same letter enclosed in brackets are significantly different according to a two-tailed t test $(P=0.05)$. Mean values followed by the same letter not enclosed in brackets are not significantly different.

in autumn, water content on the latter date was more uniformly distributed, both horizontally $(5.8 \leq \mathrm{CV} \leq 8.0 \%)$, and vertically given that $\mathrm{CFO} 2$ and $\mathrm{CFM} 2$ were characterized by equal mean $\theta_{0}$ values. Reduced transpiration and lack of canopy interception were considered responsible for the higher soil moisture content observed in the glade of Ciavolo on the second date (ratio between mean $\theta_{0}$ values in CGM2 and CFM2 equal to 1.7).

As expected, the pine duff at both sites (Ciavolo and Javea) was characterized by significantly lower bulk density and higher organic matter content than the underlying mineral soil (Table 2). In particular, the ratio between the bulk density of the duff and that of the mineral soil varied in the range 0.51-0.68, whereas the same ratio for OM ranged between 3.1 and 5.5. In general, the differences between the properties of the two sampled layers were more pronounced at Javea than at Ciavolo (Table 2). At this second site, the mean values of $\rho_{b}$ and OM in the duff did not change in the spell between the two sampling dates (CFO1 and CFO2), whereas a significant reduction by a factor of 0.93 and 0.84 , respectively, was found for the subsoil (CFM1 and CFM2) (Table 2). At the second sampling date, the two mineral soils of Ciavolo (CFM2 and CGM2) showed significant different values of $\rho_{b}$ and OM. However, the variability of point measurements of bulk density and organic matter for the mineral soils of Ciavolo was generally limited $\left(1.01 \leq \rho_{b} \leq\right.$ $\left.1.29 \mathrm{~kg} \mathrm{~m}^{-3} ; 3.8 \leq \mathrm{OM} \leq 5.0 \%\right)$ and within the range encountered for similar soil types (Bagarello et al., 2014).

The WDPT tests conducted at the glade site of Ciavolo (CGM2) showed no occurrence of water repellency given that the water drops placed on the soil surface always infiltrated in less than $5 \mathrm{~s}$ (WDPT $<5 \mathrm{~s}$ ). The very fast infiltration time precluded the estimation of statistics for WDPT in this site and, therefore, these data were excluded from the following analysis. The hypothesis of WDPT data distributed according to a lognormal distribution was never rejected except for the duff layer of Javea (JFO1) for which neither the normal or the log-normal distributions described the WDPT data. The normal distribution was rejected in two additional cases and, when both the normal and log-normal distributions were not rejected, the Lilliefors statistic was generally lower for the log-transformed data. Therefore, the log-normal distribution was assumed for WDPT data and results summarized by calculating the geometric mean, GM, and the associated CV (Lee et al., 1985).

In both forest sites, the surface duff exhibited a marked SWR (Table 3), whereas the subsurface layer was hydrophobic only at the Ciavolo site where WDPT ranged from a minimum of 100 up to $4425 \mathrm{~s}$ (Table 3). According to the classification by Dekker and Ritsema (1994), the pine duff was classified as severely water repellent. The WDPT of the duff was from 2 to 5.3 times that of the mineral soil layer at Ciavolo, depending on sampling date, and 370 times higher at Javea. In the spell between the two sampling campaigns conducted at Ciavolo, the WDPT decreased by a not significant $14 \%$ in the duff layer and increased by a factor of 2.5 in the mineral subsoil (Table 3). The observed decrease of WDPT was probably a consequence of the well document decrease of SWR as the initial water content increases (i.e., de Jonge et al., 1999; Dekker and Ritsema, 1994; Fér et al., 2016; Lichner et al., 2013a). For the mineral layer, the hydrophobicity increased notwithstanding the soil water content did not change and the organic matter content decreased (Table 2) thus suggesting that amphiphilic hydrophobic compounds were probably leached from the surface duff as consequence of rainfall that occurred in autumn (Vogelmann et al., 2013). This interpretation was supported by the large 
Table 3. Statistics of water drop penetration time, WDPT, water repellency cessation time, WRCT, repellency index, RI, and modified repellency index, $\mathrm{RI}_{\mathrm{m}}$, for different sampling depths and dates at the experimental sites of Ciavolo (C) (Italy) and Javea (J) (Spain) where F: forest, G: glade, O: decomposed organic floor layer (duff), M: mineral soil; 1: first sampling; 2: second sampling, $N$ : sample size.

\begin{tabular}{|c|c|c|c|c|c|c|c|}
\hline & \multicolumn{5}{|c|}{ Ciavolo } & \multicolumn{2}{|c|}{ Javea } \\
\hline & CFO1 & CFO2 & CFM1 & CFM2 & CGM2 & JFO1 & JFM1 \\
\hline & \multicolumn{7}{|c|}{ Water drop penetration time, WDPT (s) } \\
\hline$N$ & 30 & 30 & 29 & 30 & 30 & 30 & 29 \\
\hline $\min$ & 868 & 150 & 113 & 100 & & 480 & 1 \\
\hline $\max$ & 3534 & 6890 & 855 & 4425 & & 7517 & 18 \\
\hline \multirow{2}{*}{$\begin{array}{c}\text { geometric } \\
\text { mean }\end{array}$} & 1689 & 1454 & 300 & 745 & $<5$ & 2139 & 5 \\
\hline & $\mathrm{a},(\mathrm{c})$ & $\mathrm{a},(\mathrm{d})$ & (b), (c) & (b),(d) & & (e) & (e) \\
\hline $\mathrm{CV}(\%)$ & 48.4 & 182.0 & 53.6 & 136.7 & & 116.1 & 106.1 \\
\hline & \multicolumn{7}{|c|}{ Water repellency cessation time, WRCT (s) } \\
\hline$N$ & 10 & 9 & 10 & 10 & 10 & 10 & 10 \\
\hline $\min$ & 9736 & 4653 & 2446 & 1701 & 479 & 2496 & 169 \\
\hline $\max$ & 20204 & 13678 & 8502 & 8772 & 861 & 11250 & 761 \\
\hline \multirow{2}{*}{$\begin{array}{c}\text { geometric } \\
\text { mean }\end{array}$} & 13933 & 8908 & 4344 & 3534 & 631 & 6268 & 386 \\
\hline & (a),(c) & (a),(d) & $\mathrm{b},(\mathrm{c})$ & $\mathrm{b},(\mathrm{d}),(\mathrm{e})$ & (e) & (f) & (f) \\
\hline $\mathrm{CV}(\%)$ & 25.4 & 35.3 & 45.0 & 56.4 & 21.5 & 64,2 & 54,2 \\
\hline & \multicolumn{7}{|c|}{ Repellency index, RI (-) } \\
\hline$N$ & 100 & 100 & 100 & 100 & 100 & 100 & 100 \\
\hline $\min$ & 11.9 & 10.3 & 1.9 & 3.3 & 1.4 & 5.7 & 0.4 \\
\hline $\max$ & 224.0 & 129.6 & 27.7 & 31.2 & 4.7 & 79.5 & 4.3 \\
\hline \multirow{2}{*}{$\begin{array}{c}\text { geometric } \\
\text { mean }\end{array}$} & 55.1 & 32.5 & 6.1 & 9.7 & 2.7 & 22.4 & 1.3 \\
\hline & (a), (c) & (a),(d) & (b), (c) & (b),(d),(e) & (e) & (f) & (f) \\
\hline \multirow[t]{4}{*}{ CV (\%) } & 68.8 & 70.5 & 69.7 & 54.6 & 26.1 & 63.7 & 64.8 \\
\hline & \multicolumn{7}{|c|}{ Mean repellency index, RI (-), according to Tillman et al. (1989) } \\
\hline & 57.2 & 28.0 & 6.5 & 9.9 & 2.7 & 22.5 & 1.2 \\
\hline & \multicolumn{7}{|c|}{ Modified repellency index, $\mathrm{RI}_{\mathrm{m}}(-)$} \\
\hline$N$ & 8 & 10 & 10 & 8 & 10 & 10 & 9 \\
\hline $\min$ & 16.8 & 6.3 & 6.9 & 10.4 & 4.6 & 2.8 & 1.7 \\
\hline $\max$ & 60.3 & 57.3 & 23.2 & 17.8 & 7.9 & 14.2 & 3.6 \\
\hline \multirow{2}{*}{ GM } & 29.7 & 21.3 & 13.5 & 13.4 & 5.8 & 5.6 & 2.1 \\
\hline & $\mathrm{a},(\mathrm{c})$ & $\mathrm{a},(\mathrm{d})$ & $\mathrm{b},(\mathrm{c})$ & $\mathrm{b},(\mathrm{d}),(\mathrm{e})$ & (e) & (f) & (f) \\
\hline CV (\%) & 48.2 & 76.1 & 43.3 & 15.8 & 16.3 & 53.1 & 24.1 \\
\hline
\end{tabular}

Mean values followed by the same letter enclosed in brackets are significantly different according to a two-tailed t test $(P=0.05)$. Mean values followed by the same letter not enclosed in brackets are not significantly different.

difference in WDPT observed for the mineral clay-loam soil layer under the pine forest and the spontaneous grass. Indeed, WDPT $<5 \mathrm{~s}$ was observed in $100 \%$ of cases in the soil of the glade site (CGM2) whereas, in the mineral soil of forest site (CFM2), the minimum value of WDPT was equal to $100 \mathrm{~s}$. A different result was obtained for the mineral subsoil of Javea (JFM1) that showed wettable conditions (WDPT $\leq 5 \mathrm{~s}$ ) in $37 \%$ of cases, thus confirming that the dynamic of hydrophobic compounds in the subsoil is mostly unknown and needs further analysis (Buczko et al., 2002, 2005; Jungerius and Dejong, 1989).

Large variability of results is rather common for WDPT measurements. García et al. (2005) found $57 \%$ of wettable field-moist samples $(N=89)$ at depths $0-0.025 \mathrm{~m}$ under the Pinus pinea trees in southern Spain, which is consistent with the findings of Lichner et al. (2013a) for a Pinus sylvestris forest in Slovakia $(N=39)$. These authors reported relative frequencies of strongly, severely and extremely water repellent conditions equal to 23,18 and $5 \%$, respectively.

McKissock et al. (1998) found that WDPT was directly correlated to OM. This investigation also showed a statistically significant positive relationship $\left(R^{2}=0.830\right)$ between mean WDPT and OM values $(N=7)$ (Figure 2$)$. This means that the amount of soil OM has a strong influence on the persistence of SWR. However, the chemical characteristics of OM influence to a greater extent SWR and soil wettability can be better interpreted if organic composition is considered (Buczko et al., 2005; Ellerbrock et al., 2005; Vogelmann et al., 2013). In fact, the relatively small amount of hydrophobic compounds could not be necessarily proportional to the amount of total OM (Doerr et al., 2000). A linear increasing relationship was found between WDPT and the potential wettability index that is the proportion of hydrophobic to hydrophilic functional groups (Fér et al., 2016; Leue et al., 2015). A similar result was found by Ellerbrock et al. (2005) despite SWR was not directly correlated with OM. Analysis of OM composition was not conducted in this study but these findings could explain the very different behavior observed in terms of WDPT for the clay-loam soils of CFM2 and CGM2 sites that were characterized by approximately the same amount of OM (Figure 2).

Minidisk infiltration tests conducted with ethanol as infiltrating liquid were in line with the infiltration theory that prescribes a more or less prolonged transient phase in which infiltration rate, $i\left(\mathrm{~L} \mathrm{~T}^{-1}\right)$ decreases, followed by a steady state infiltration phase in which infiltration rate is practically constant. 


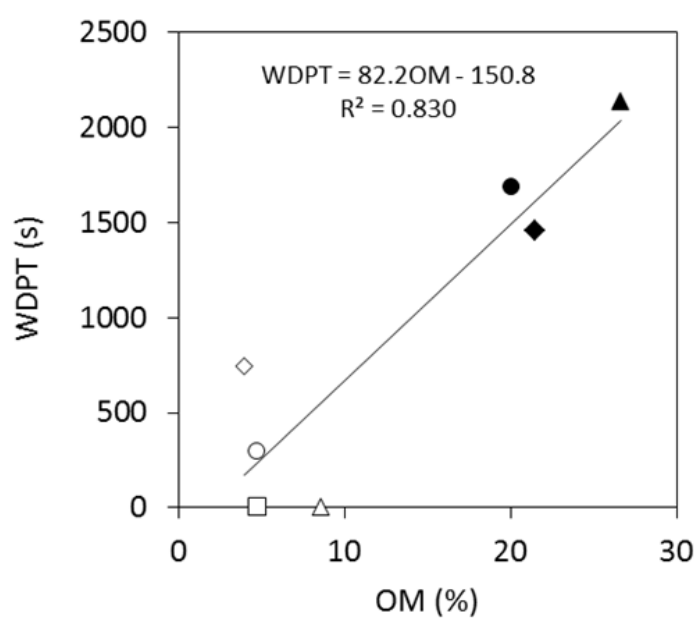

Fig. 2. Relationship between the organic matter $(\mathrm{OM})$ content and the water drop penetration time (WDPT) for the different vegetation covers, sampling depths and initial soil water contents of the experimental sites of Ciavolo (Italy) and Javea (Spain) (• CFO1; $\bullet \mathrm{CFO}$; $\bigcirc \mathrm{CFM} 1 ; \diamond \mathrm{CFM} 2 ; \square \mathrm{CGM} 2 ; \Delta \mathrm{JFO} 1 ; \triangle \mathrm{JFM} 1)$.

This behaviour is shown in Figure 3a in which normalized infiltration rate (i.e., $i / i_{\max }$ ) is plotted as function of normalized time $\left(t / t_{\max }\right)$. In the initial stage of water infiltration, hydrophobicity prevented water entry into the soil thus resulting in a low infiltration rate (Figure 3b). Following wetting of hydrophobic compounds, infiltration rate increased at larger duration of the run. As highlighted by bold lines in Figure 3b, an increase of infiltration rate at late time was also detected for the mineral soils of Ciavolo glade (CGM2) and Javea (JFM1) that were classified as wettable according to the WDPT tests. The occurrence of hydrophobicity was even more evident when the cumulative water infiltration data were plotted as function of the square root of time. All water infiltration tests exhibited a clear "hockey-stick-like" shape that allowed calculation of WRCT as the intersection point of two straight lines, representing the initial and the late stages of $I$ vs. $t^{0.5}$ relationships (Lichner et al., 2013b) (Figure 4). An upward concave shape of the $I$ vs. $t^{0.5}$ plot is predicted by the infiltration theory also for wetta- ble soils and could complicate the assessment of SWR. However, transition in this case is gradual and occurs relatively soon for MDI experiments as consequence of passage from the initial stage of infiltration, in which flow is dominated by vertical capillarity, to a stage in which infiltration is dominated by both vertical gravity and lateral capillarity (Vandervaere et al., 2000).

For each sampling condition, WRCT data were better described by a log-normal than a normal distribution. The GM of WRCT measured in the duff (CFO1, CFO2 and JFO1) was up to 16 times that of the corresponding underlying mineral soils (CFM1, CFM2 and JFM1) (Table 3) but differences by a factor of 5.6-6.9 were found between the mineral soils of the forest (CFM1 and CFM2) and the glade (CGM2) thus confirming that pine stands influence the hydrophobic characteristics of deeper soil layer at Ciavolo. The log-transformed values of WRCT, determined under different conditions of vegetation, sampling depth and initial soil water content at the experimental sites $(N$ $=7)$, were significantly correlated $\left(R^{2}=0.925\right)$ to the corresponding $\log (\mathrm{WDPT})$ values (Figure 5$)$. The regression line was characterized by an intercept greater than zero and a slope lower than one (Figure 5) and the discrepancies between WRCT and WDPT were more pronounced for low values of hydrophobicity and decreased as SWR increased. In other terms, a higher ability of WRCT to detect weak SWR phenomena was observed, as compared to the more traditional WDPT test. Therefore, the WRCT, determined from a single water infiltration experiment conducted by the MDI, seems potentially more suitable to assess "sub-critical" repellency that occurs when the water-solid contact angle is less than $90^{\circ}$ but not zero (Tillman et al., 1989). Under these circumstances, water infiltration rate is reduced but not prevented at all, as in the case of severe hydrophobicity.

For all ethanol and water infiltration tests, $S_{e}$ and $S_{w}$ estimation was successfully conducted given that it was always possible to select at least three initial data denoting a linear $I$ vs. $\mathrm{t}^{0.5}$ relationship. As common for most soil hydrodynamic properties (e.g., Warrick, 1998), the log-normal distribution better described the empirical frequency distribution of RI at each experimental site due to the high level of heterogeneity and positive skewness of the data. Statistics for RI confirmed the
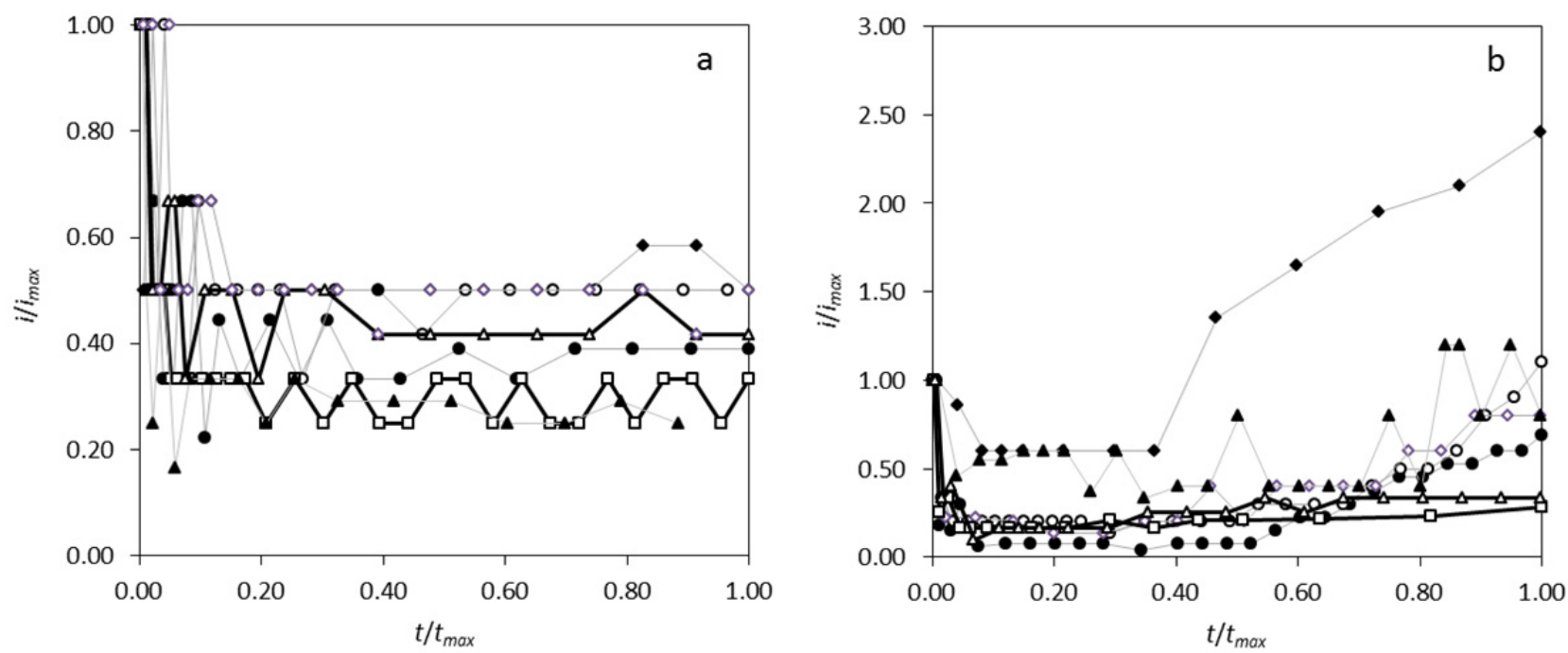

Fig. 3. Examples of normalized infiltration rate, $i / i_{\max }(-)$, vs. normalized time, $t / t_{\max }(-)$, data collected during minidisk infiltrometer tests conducted at the experimental sites with: a) ethanol and b) water as infiltrating liquids $(\bullet \mathrm{CFO} 1 ; \bullet \mathrm{CFO} 2 ; \circ \mathrm{CFM} 1 ; \diamond \mathrm{CFM} 2$; $\square \mathrm{CGM} 2$; $\triangle \mathrm{JFO} 1 ; \triangle \mathrm{JFM} 1$; infiltration data in bold lines were collected in sites that were classified as wettable according to WDPT test). 


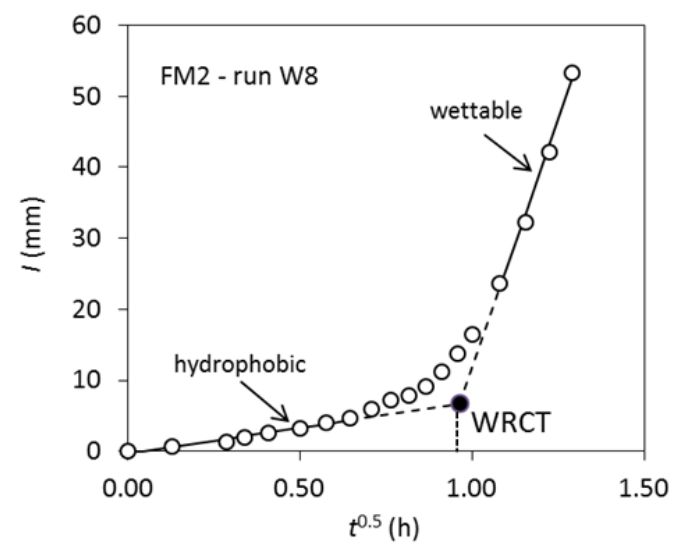

Fig. 4. Example of the estimation of the water repellency cessation time (WRCT) for a MDI experiment conducted with water in the mineral sublayer of the Ciavolo pine forest.

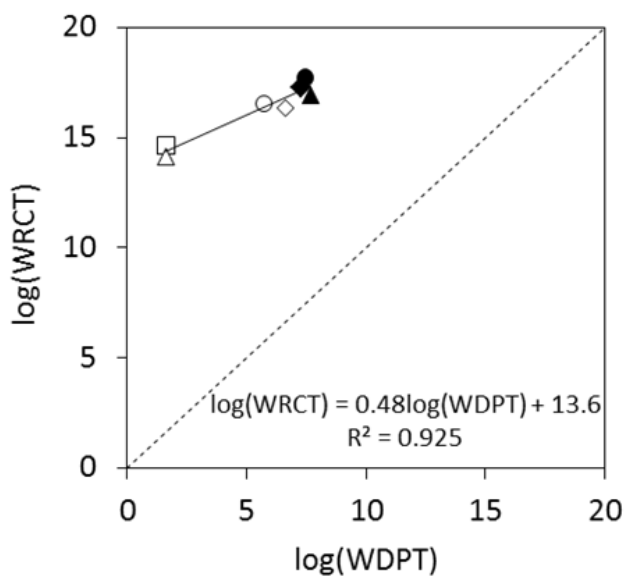

Fig. 5. Relationship between water drop penetration time (WDPT) and water repellency cessation time (WRCT) for different vegetation covers, sampling depths and initial soil water contents of the experimental sites of Ciavolo (Italy) and Javea (Spain) ( $\bullet$ CFO1; $\bullet \mathrm{CFO} 2 ; \circ \mathrm{CFM} 1 ; \diamond \mathrm{CFM} 2 ; \square \mathrm{CGM} 2 ; \triangle \mathrm{JFO} 1 ; \triangle \mathrm{JFM} 1)$.

influence of pine vegetation on SWR already shown by the other indices (Table 3). Mean RI values in the duff of the forest sites (CFO1, CFO2 and JFO1) were from 3.3 to 17 times higher than the corresponding RI values measured in the subsoil (CFM1, CFM2 and JFM1). Furthermore, the ratio between the mean RI in the forest and the glade soils of Ciavolo ranged from 2.2 to 20 according to the different sampling depths and dates (Table 3). The differences in RI values between the forest and the glade sites of Ciavolo are in agreement with those detected by Lichner et al. (2012) in a sandy soil at Sekule (southwestern Slovakia). They found that the mean RI values in the duff under Pinus sylvestris trees were from 3.6 to 11.9 times higher than the mean RI values estimated in the glade (covered with the biological soil crust) and grassland soils.

In agreement with the vertical dynamics of hydrophobic compounds suggested by the WDPT tests, RI at Ciavolo decreased in the duff and increased in mineral subsoil in the spell between the two samplings (Table 3). Only one sampling campaign was conducted at Javea and analysis of temporal evolution of SWR is not possible. However, the wettable or weak hydrophobic conditions detected for the mineral subsoil by WDPT, WRCT and RI indices suggest absence of leaching phenomena in this site. Indeed, minidisk infiltration tests conducted with ethanol yielded steady-state infiltration rates in the surface organic layer of Javea (JFO1) that were 3.8-5.8 times lower than those in the corresponding layer at Ciavolo (CFO1 and $\mathrm{CFO} 2$ ). Given that steady-state infiltration rate is a close estimate of soil hydraulic conductivity and that infiltration process with ethanol is not influenced by hydrophobicity, it was concluded that the different extent of vertical SWR observed in the two sites was a consequence of the different transmission properties of the organic layer overlaying the mineral soil.

The geometric mean values of RI were practically coincident with the mean RI values calculated according to Tillman et al. (1989) as adjusted ratio of the mean of $S_{e}$ and $S_{w}$ at each of seven experimental conditions (Table 3 ). In other terms, conducting pairwise infiltration experiments with ethanol and water to determine mean values of $S_{e}$ and $S_{w}$ yields a mean RI value equal to that obtained applying the combination procedure suggested by Pekárová et al. (2015) with the advantage that this last procedure allows a straightforward quantification of SWR variability.

The sharp increase in the slope of the cumulative water infiltration data plotted in the form $I$ vs. $t^{0.5}$ (Figure 4) suggested to propose a modified repellency index, $\mathrm{RI}_{\mathrm{m}}$, defined as the ratio of the sorptivities estimated at the late and early stages of a single water infiltration test conducted by MDI. The statistics of $\mathrm{RI}_{\mathrm{m}}$, reported in Table 3, confirmed the differences between the surface duff and the underlying mineral soil for both Ciavolo and Javea sites and between the mineral soils in the forest (CFM2) and the glade (CGM2) but not between the first and the second sampling date at the forest site of Ciavolo.

Independently of the sampled layer and the initial soil water content, the spatial variability of the repellency indices deduced from MDI experiments were comparable (Table 3) and generally lower in the glade site than in the forest ones. Estimation of SWR by WDPT measurements yielded in some cases larger spatial variability. The soil surface area sampled in a drop scale infiltration test is of the order of $0.14 \mathrm{~cm}^{2}$ whereas the MDI samples a 100 times larger surface area. Therefore, the observed differences in CVs can be considered a consequence of the different spatial support of the two considered field tests (Moody and Schlossberg, 2010).

Table 4. Correlation matrix of repellency indices for the different vegetation covers, sampling depths and initial soil water contents of the experimental sites of Ciavolo (Italy) and Javea (Spain).

\begin{tabular}{|l|l|l|l|l|}
\hline & $\log (\mathrm{WDPT})$ & $\log (\mathrm{WRCT})$ & $\log (\mathrm{RI})$ & $\log \left(\mathrm{RI}_{\mathrm{m}}\right)$ \\
\hline $\log (\mathrm{WDPT})$ & 1 & & & \\
\hline $\log (\mathrm{WRCT})$ & $\mathbf{+ 0 . 9 6 1 7}$ & 1 & & \\
\hline $\log (\mathrm{RI})$ & $\mathbf{+ 0 . 7 9 5 7}$ & $\mathbf{+ 0 . 8 5 1 5}$ & 1 & 1 \\
\hline $\log \left(\mathrm{RI}_{\mathrm{m}}\right)$ & +0.6847 & $\mathbf{+ 0 . 8 0 9 5}$ & $\mathbf{+ 0 . 8 1 0 2}$ & 1 \\
\hline
\end{tabular}

Values in bold are significantly different from zero according to the Student $t$-test $(P=0.05)$. 

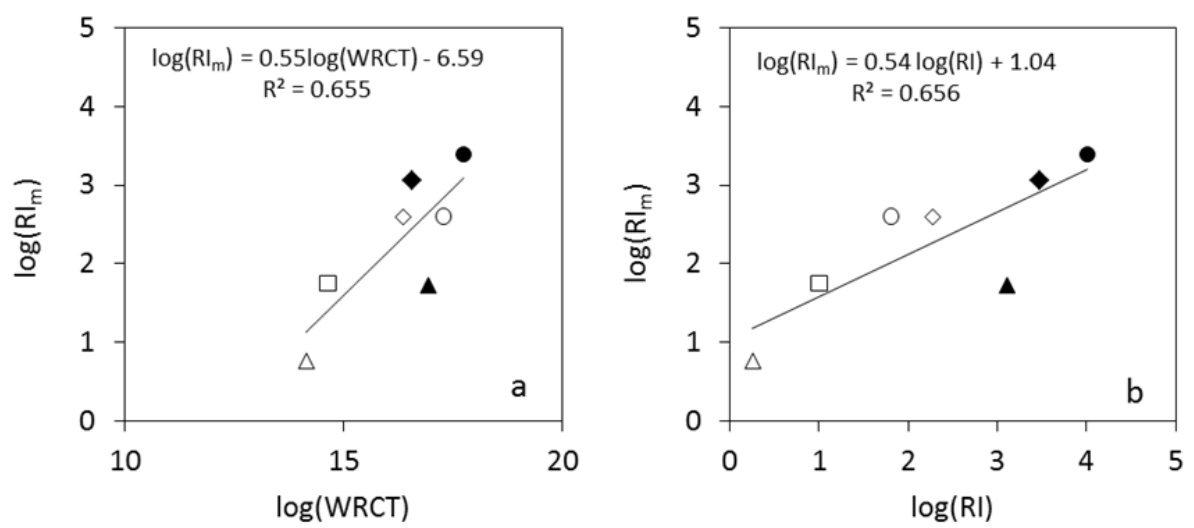

Fig. 6. Regression lines between the log-transformed values of (a) water repellency cessation time (WRCT) and modified repellency index $\left(R I_{m}\right)$, (b) repellency index (RI) and modified repellency index $\left(\mathrm{RI}_{\mathrm{m}}\right)$ for different vegetation covers, sampling depths and initial soil water contents at the experimental sites of Ciavolo (Italy) and Javea (Spain) $(\bullet \mathrm{CFO} 1 ; \bullet \mathrm{CFO} 2 ; \circ \mathrm{CFM} 1 ; \diamond \mathrm{CFM} 2 ; \square \mathrm{CGM} 2 ; \boldsymbol{\Delta} \mathrm{JFO} 1$; $\triangle \mathrm{JFM} 1)$.

The repellency indices obtained by the infiltration tests conducted by MDI were generally correlated among them and with the WDPT index (Table 4). In particular, both the original repellency index, $\mathrm{RI}$, and the modified repellency index, $\mathrm{RI}_{\mathrm{m}}$, showed a closer correspondence with WRCT than WDPT, thus confirming that the water repellency assessment conducted by infiltration-based tests (i.e., WRCT, RI, and $\mathrm{RI}_{\mathrm{m}}$ ) yields comparable results. In particular, a significant linear regression line was found between $\log (\mathrm{WRCT})$ and $\log \left(\mathrm{RI}_{\mathrm{m}}\right)$ and between $\log (\mathrm{RI})$ and $\log \left(\mathrm{RI}_{\mathrm{m}}\right)$ (Figure 6) suggesting that the modified repellency index $\mathrm{RI}_{\mathrm{m}}$, obtained from a single infiltration experiment conducted with water as infiltrating fluid, could be considered suitable for assessing the hydrologic effects of SWR by overcoming the experimental drawback of conducting two infiltration runs with different liquids (water and ethanol) in different sampling points. Despite WRCT and $\mathrm{RI}_{\mathrm{m}}$ require the same experimental information, the ratio between two slopes of the $I$ vs. $t^{0.5}$ graph appears inherently more robust and less subjective than the estimation of a single point characterizing the transition from hydrophobic to wettable conditions.

\section{CONCLUSIONS}

All the water repellency indices (WDPT, WRCT, RI and $\mathrm{RI}_{\mathrm{m}}$ ) unanimously detected severe SWR of the surface soil layer of the pine forests of Ciavolo and Javea due to the high amount of organic matter $(\mathrm{OM}>20 \%)$. However, for the clay loam soil of Ciavolo, higher hydrophobicity was observed in the mineral subsoil under the pine trees than in an adjacent glade area despite the OM content of the two investigated sites was comparable. Furthermore, SWR of the mineral subsoil increased in conjunction with autumnal rainfalls. It was hypothesized that leaching of hydrophobic compounds, such as resins and waxes from decomposing pine needles in the overlying duff, determined the observed SWR evolution. The same vertical distribution of hydrophobic compounds was not observed in the forest site of Javea where the mineral subsoil was wettable or weakly hydrophobic. In this case, WDPT, WRCT, $\mathrm{RI}$ and $\mathrm{RI}_{\mathrm{m}}$ indices were comparable to those determined in the glade area of Ciavolo. Due to lower hydraulic conductivity properties of the duff in Javea site, percolation of hydrophobic compounds to the subsoil was slowed or prevented at all, thus resulting in a sharply stratified condition with the uppermost part of the soil profile characterized by severe or extreme SWR and the immediately underlying soil being practically wettable.
The considered indices were generally correlated one another and lead to SWR estimations generally concurrent even if some discrepancies in prediction were observed. In particular, at low hydrophobicity levels, the SWR indices gathered from the MDI tests signaled SWR conditions that were not detected by the traditional WDPT index. This result confirms that the traditional WDPT test is able to discriminate between hydrophobic and wettable soil conditions but is less suitable to account for sub-critical SWR. On the other hand, infiltration experiments conducted by the MDI can disclose sub-critical conditions, that is the conditions in which infiltration is reduced but not prevented at all and may negatively affect hydrological process. Furthermore, the soil volume sampled by the MDI is more representative of small scale variability of SWR that cannot be detected by the droplet test.

The WRCT and modified repellency index $\mathrm{RI}_{\mathrm{m}}$, requiring only a single MDI experiment conducted with water, yielded SWR estimates in reasonable agreement with those obtained with the RI test. The two indices, being able to account for subcritical SWR, offer a way to quantify with a single number the complex site-specific soil wetting properties. Further investigations are necessary to test the validity of $\mathrm{WRCT}_{\text {and }} \mathrm{RI}_{\mathrm{m}}$ on different soil-vegetation associations also with the aim to define classification criteria for these repellency indices. However, they appear potentially usable for SWR assessment in alternative to the more cumbersome RI approach.

Acknowledgements. This study was supported by grants from the Università degli Studi di Palermo (project FFR 2012 and Dottorato di Ricerca in Scienze Agrarie, Forestali e Ambientali, ciclo XXIX, D50002D13+1012), the Slovak Scientific Grant Agency VEGA (project No. 2/0054/14), Ministerio de Economía and Competitividad of Spanish Government (project CGL2013- 47862-C2-1-R), Botánica Mediterránea S.L., and Montgó Natural Park. Field data in Italy and Spain were collected by V. Alagna. All authors analyzed the data and contributed to write the manuscript.

\section{REFERENCES}

Alagna, V., Bagarello, V., Di Prima, S., Iovino, M., 2016. Determining hydraulic properties of a loam soil by alternative infiltrometer techniques. Hydrol. Process., 30, 2 , $263-275$. 
Bagarello, V., Castellini, M., Di Prima, S., Iovino, M., 2014. Soil hydraulic properties determined by infiltration experiments and different heights of water pouring. Geoderma, 213, 492-501.

Beatty, S.M., Smith, J.E., 2013. Dynamic soil water repellency and infiltration in post-wildfire soils. Geoderma 192, 160172.

Buczko, U., Bens, O., Fischer, H., Hüttl, R.F., 2002. Water repellency in sandy luvisols under different forest transformation stages in northeast Germany. Geoderma, 109, $1-2,1-18$.

Buczko, U., Bens, O., Hüttl, R.F., 2005. Variability of soil water repellency in sandy forest soils with different stand structure under Scots pine (Pinus sylvestris) and beech (Fagus sylvatica). Geoderma, 126, 3-4, 317-336.

Cerdà, A. 1996. Seasonal variability of infiltration rates under contrasting slope conditions in southeast Spain. Geoderma, 69, 217-232.

Cerdà, A., Doerr, S.H., 2007. Soil wettability, runoff and erodibility of major dry-Mediterranean land use types on calcareous soils. Hydrol. Process., 21, 17, 2325-2336.

DeBano, L.F., 2000. Water repellency in soils: a historical overview. J. Hydrol., 231-232, 4-32.

de Jonge, L.W., Jacobsen, O.H., Moldrup, P., 1999. Soil water repellency: effects of water content, temperature, and particle size. Soil Sci. Soc. Am. J., 63, 3, 437-442.

Dekker, L.W., Ritsema, C.J., 1994. How water moves in a water repellent sandy soil. 1. Potential and actual water repellency. Water Resour. Res., 30, 9, 2507-2517.

Doerr, S.H., 1998. On standardizing the 'Water Drop Penetration Time' and the 'Molarity of an Ethanol Droplet' techniques to classify soil hydrophobicity: A case study using medium textured soils. Earth Surf. Proc. Landf., 23, 7, 663-668.

Doerr, S.H., Shakesby, R.A., Walsh, R.P.D., 1996. Soil hydrophobicity variations with depth and particle size fraction in burned and unburned Eucalyptus globulus and Pinus pinaster forest terrain in the Águeda Basin, Portugal. Catena, 27, 1, 25-47.

Doerr, S.H., Shakesby, R.A., Walsh, R.P.D., 2000. Soil water repellency: its causes, characteristics and hydrogeomorphological significance. Earth-Sci. Rev., 51, 1-4, 33-65.

Ebel, B.A., Moody, J.A., Martin, D.A., 2012. Hydrological conditions controlling runoff generation immediately after wildfire. Water Resour. Res., 48, W03529.

Ellerbrock, R.H., Gerke, H.H., Bachmann, J., Goebel, M.-O., 2005. Composition of organic matter fractions for explaining wettability of three forest soils. Soil Sci. Soc. Am. J., 69, 1, 57-66.

Fér, M., Leue, M., Kodešová, R., Gerke, H.H., Ellerbrock, R.H., 2016. Droplet infiltration dynamics and soil wettability related to soil organic matter of soil aggregate coatings and interiors. J. Hydrol. Hydromech., 64, 2, 111120.

García, F.J.M., Dekker, L.W., Oostindie, K., Ritsema, C.J., 2005. Water repellency under natural conditions in sandy soils of southern Spain. Soil Research, 43, 3, 291-296.

Iovino, M., Castellini, M., Bagarello, V., Giordano, G., 2016. Using static and dynamic indicators to evaluate soil physical quality in a sicilian area. Land Degradation \& Development, 27, 2, 200-210.

Hallett, P.D., Baumgartl, T., Young, I.M., 2001. Subcritical water repellency of aggregates from a range of soil management practices. Soil Sci. Soc. Am. J., 65, 1, 184-190.
Hallin, I., Douglas, P., Doerr, S.H., Bryant, R., 2013. The role of drop volume and number on soil water repellency determination. Soil Sci. Soc. Am. J., 77, 5, 1732-1743.

Helsel, D.R., Hirsch, R.M., 2002. Statistical methods in water resources. Techniques of Water resources investigations, Book 4, chapter A3. U.S. Geological Survey. 522 p. Publication available http://water.usgs.gov/pubs/twri/twri4a3/

Hunter, A.E., Chau, H.W., Si, B.C., 2011. Impact of tension infiltrometer disc size on measured soil water repellency index. Can. J. Soil Sci., 91, 1, 77-81.

Jungerius, P.D., Dejong, J.H., 1989. Variability of water repellence in the dunes along the Dutch coast. Catena, 16, 45, 491-497.

Lee, D.M., Reynolds, W.D., Elrick, D.E., Clothier, B.E., 1985. A comparison of three field methods for measuring saturated hydraulic conductivity. Can. J. Soil Sci., 65, 3, 563-573.

Leue, M., Gerke, H.H., Godow, S.C., 2015. Droplet infiltration and organic matter composition of intact crack and biopore surfaces from clay-illuvial horizons. Journal of Plant Nutrition and Soil Science, 178, 2, 250-260.

Lichner, L., Holko, L., Zhukova, N., Schacht, K., Rajkai, K., Fodor, N., Sándor, R., 2012. Plants and biological soil crust influence the hydrophysical parameters and water flow in an aeolian sandy soil. J. Hydrol. Hydromech., 60, 4, 309318.

Lichner, L., Capuliak, J., Zhukova, N., Holko, L., Czachor, H., Kollar, J., 2013a. Pines influence hydrophysical parameters and water flow in a sandy soil. Biologia, 68, 6, 1104-1108.

Lichner, L., Hallett, P.D., Drongová, Z., Czachor, H., Kovacik, L., Mataix-Solera, J., Homolák, M., 2013b. Algae influence the hydrophysical parameters of a sandy soil. Catena, 108, 58-68.

Lilliefors, H.W., 1967. On the Kolmogorov-Smirnov test for normality with mean and variance unknown. J. Am. Stat. Assoc., 62, 318, 399-402.

Ma'shum, M., Farmer, V., 1985. Origin and assessment of water repellency of a sandy South Australian soil. Soil Research, 23, 4, 623-626.

McKissock, I., Gilkes, R.J., Harper, R.J., Carter, D.J., 1998. Relationships of water repellency to soil properties for different spatial scales of study. Soil Research, 36, 3, 495-508.

Moody, D.R., Schlossberg, M.J., 2010. Soil water repellency index prediction using the molarity of ethanol droplet test. Vadose Zone J., 9, 4, 1046-1051.

Nelson, D.W, Sommers, L.E., 1996. Methods of Soil Analysis. Part 3. Chemical Methods. Soil Science Society of America Book Series, no.5, pt. 3. Soil Science Society of America, American Society of Agronomy, Madison, WI, pp. 9611010.

Nyman, P., Sheridan, G., Lane, P.N.J., 2010. Synergistic effects of water repellency and macropore flow on the hydraulic conductivity of a burned forest soil, south-east Australia. Hydrol. Process., 24, 2871-2887.

Pekárová, P., Pekár, J., Lichner, L., 2015. A new method for estimating soil water repellency index. Biologia, 70, 11, 1450-1455.

Philip, J.R., 1957. The theory of infiltration: 4. Sorptivity and algebraic infiltration equations. Soil Sci., 84, 257-264.

Rodríguez-Alleres, M., Benito, E., de Blas, E., 2007. Extent and persistence of water repellency in north-western Spanish soils. Hydrol. Process., 21, 17, 2291-2299.

Sepehrnia, N., Hajabbasi, M.A., Afyuni, M., Lichner, L., 2016. Extent and persistence of water repellency in two Iranian soils. Biologia, 71, 1137-1143. 
Soil Survey Staff, 2014. Keys to Soil Taxonomy. 12th ed. NRCS, Washington, DC.

Tillman, R.W., Scotter, D.R., Wallis, M.G., Clothier, B.E., 1989. Water-repellency and its measurement by using intrinsic sorptivity. Aust. J. Soil Res., 27, 4, 637-644.

Tschapek, M., 1984. Criteria for determining the hydrophilicity-hydrophobicity of soils. Zeitschrift für Pflanzenernährung und Bodenkunde, 147, 2, 137-149.

Vandervaere, J.P., Vauclin, M., Elrick, D.E., 2000. Transient flow from tension infiltrometers: II. Four methods to determine sorptivity and conductivity. Soil Sci. Soc. Am. J., 64, 1272-1284.

Van't Woudt, B.D., 1959. Particle coatings affecting the wettability of soils. Journal of Geophysical Research, 64, 2, 263-267.
Vogelmann, E.S., Reichert, J.M., Prevedello, J., Consensa, C.O.B., Oliveira, A.É., Awe, G.O., Mataix-Solera, J., 2013. Threshold water content beyond which hydrophobic soils become hydrophilic: The role of soil texture and organic matter content. Geoderma, 209-210, 177-187.

Warrick, A.W., 1998. Appendix 1: Spatial variability. In: Hillel, D. (Ed.): Environmental Soil Physics. Academic Press, San Diego, pp. 655-675.

Watson, C.L., Letey, J., 1970. Indices for characterizing soilwater repellency based upon contact angle-surface tension relationships. Soil Sci. Soc. Am. J., 34, 6, 841-844.

Received 9 August 2016 Accepted 6 December 2016 